Int. J. Dev. Biol. 54: 1079-1087 (2010)

doi: $10.1387 / \mathrm{ijdb} .093047 \mathrm{fd}$

\title{
Allantois and placenta as developmental sources of hematopoietic stem cells
}

\author{
FRANÇOISE DIETERLEN-LIÈVRE*,1 CATHERINE CORBEL ${ }^{2}$ and JOSSELYNE SALAÜN1 \\ 1'Institut d'Embryologie Cellulaire et Moléculaire du CNRS et du Collège de France, Nogent-sur-Marne, \\ France and ${ }^{2}$ Mammalian Developmental Epigenetics Group, CNRS UMR3215, INSERM U934, \\ Institut Curie, Paris, France
}

\begin{abstract}
While the aortic region, the para-aortic splanchnopleura/aorta-gonads-mesonephros (P-Sp/AGM) is currently considered as the source of definitive hematopoietic stem cells during development, the mouse placenta has been found to generate large numbers of these cells and to remain functional in this respect for a longer period than the P-Sp/AGM. The fetal component, which derives from the fused allantois and chorion, is responsible for this activity. We and others have shown that the pre-fusion allantois (before the stage of 6 pairs of somites) is able to yield clonogenic progenitors, provided that it is pre-cultured in toto before it is dissociated into single cells and seeded in semi-solid medium. Thus placental hematopoiesis can be concluded to derive from intrinsic precursors. It is similar in this regard to the yolk sac which both produces hematopoietic progenitors and supports their multiplication and differentiation. Hematopoietic activity, detected by in vitro colony assays, has also been recently uncovered in the human placenta. According to the data available, this newly identified source probably provides a large number of HSC during development and must play a foremost role in founding the definitive hematopoietic system.
\end{abstract}

KEY WORDS: allantois, placenta, mouse, hematopoietic stem cell

\section{Introduction}

During vertebrate development hematopoiesis is sequentially carried out by distinct organs, some of which allow the differentiation of common lineages, while others promote unique lineages. Thus yolk sac, mammalian fetal liver, spleen and bone marrow ensure the differentiation of myeloid lineages while $T$ and $B$ lymphoid lineages become amplified and instructed respectively in the thymus and in the bone marrow or the avian-specific bursa of Fabricius. All these organ rudiments include a mesodermal stroma which provides the specific microenvironment responsible for differentiation of the hematopoietic lineages. Some rudiments are purely mesodermal (bone marrow, spleen) while in others endoderm is also a component of the stroma (yolk sac, fetal liver, thymus, bursa).

Hematopoietic Stem Cells (HSC), the central players in the activity of the hematopoietic system, though mesodermal in origin, do not derive from the mesoderm of the stroma, except in the case of the yolk sac, for many years the only site in the embryo known to produce its own HSC (Moore and Owen, 1965; Le Douarin and Jotereau, 1973; Le Douarin et al., 1975; Pardanaud et al., 1989). As these cells are endowed with extensive migration properties, their ontogenic origin has been actively investigated since the 1960ies and still is a controversial issue (Yoshimoto et al., 2008). Indeed intra-embryonic hematopoietic organs become seeded by HSC, each at a precisely specified stage of ontogeny, as established by explanting early rudiments either in vivo or in vitro. The extrinsic origin of hematopoietic cells was diagnosed in vivo by means of appropriate markers, while in vitro, rudiments explanted before the stage of colonization did not become hematopoietic. The mammalian fetal liver for instance initiates its colonization by the stage of 28 to 32 pairs of somites (Johnson and Moore, 1975; Houssaint, 1981; Cudennec et al.,1982). This applies to all the organs which carry out hematopoiesis, with the exception of the yolk sac, so that, when these questions were first

\footnotetext{
Abbreviations used in this paper: BFU-E, burst forming unit-erythroid; CFC, colony forming cells; EPC, ectoplacental cone; Ery-CFC, erythroid colony forming cells; GFP, green fluorescent protein; HSC, hematopoietic stem cells; HPP-CFC, high proliferation potential-colony forming cells; ICM, inner cell mass; LTR-HSC, long term repopulating-hematopoietic stem cells; P-Sp/AGM, para-aortic splanchnopleura/aorta-gonads-mesonephros.
}

*Address correspondence to: Françoise Dieterlen-Lièvre. 6 rue de Bellechasse 75007 France. e-mail: francoise.dieterlen@club-internet.fr

Final, author-corrected PDF published online: 21 May 2010.

ISSN: Online 1696-3547, Print 0214-6282

(๑) 2010 UBC Press

Printed in Spain 
submitted to experimentation, all HSC were assumed to have a common origin and the yolk sac was proposed as the unique source of these cells (Moore and Owen, 1967).

Later investigations in the avian, amphibian, and finally murine models (reviews in Dieterlen-Lièvre et al., 2001; Turpen, 2001; Dzierzak and Oostendorp, 2001; Dzierzak and Medvinsky, 2008) were to show that the yolk sac progenitors contribute mainly to the primary erythroid lineage and marginally to the next red cell lineage (Beaupain et al., 1979; Palis et al., 1999) then become extinct (with some species-specific exceptions in amphibians). The region of the aorta (or, in amphibians, the so-called dorsal compartment) was next identified as a site producing HSC in embryos with 18 to 40 pairs of somites (review in Durand and Dzierzak, 2005). This region, considered as the ultimate source of HSC, is the focus of many current investigations in the mouse and human embryo. In the mouse embryo, cells fated to hematopoiesis in this region were shown to evolve within a narrow developmental time frame, from short-term self-renewability (socalled progenitors) to long-term renewability, the latter capacity being the hallmark of true HSC. The peri-aortic tissues, which give rise sequentially to these two types of progenitors, became known as Para-aortic Splanchnopleura (P-Sp) (Godin et al., 1993) and Aorta-Gonad-Mesonephros (AGM), (Medvinsky et al., 1993), the two terms designating the same anatomical region at two successive steps of development ( $0-25$ somites and $25-40$ somites). As a matter of fact, now that the role of the aortic endothelium in the production of HSC is well established (Jaffredo et al. 1998; Zovein et al. 2008; Dieterlen-Lièvre and Jaffredo, 2009), as well as the more general notion of "hemogenic endothelium" (Eilken et al., 2009; Lancrin et al., 2009; Dieterlen-Lièvre and Jaffredo, 2009) it appears timely to revise this terminology.

More recently the placenta has been added to the list of organs which sustain hematopoietic activity during development of the fetus (Alvarez-Silva et al., 2003; Gekas et al., 2005; Ottersbach and Dzierzak, 2005). While the presence of reconstituting HSC (Till and McCulloch, 1961; Dancis etal., 1968; Dancis etal., 1977) and of B lymphoid progenitors (Melchers 1979) in the placenta has been reported many years ago, a contribution of the placenta to fetal hematopoiesis was not seriously considered then. These reports were published at a time when little was known about the ontogenic emergence of HSC in mammals and a possible role of the placenta in this process was not anticipated. Melchers (1979) for instance, interpreted B progenitors present in the placenta as resulting from circulating HSC derived from the yolk sac, according to the dominant theory of the time.

We have shown that the placenta is rich in clonogenic progenitors (Alvarez-Silva et al., 2003). The presence of reconstituting HSC was thereafter established (Gekas et al., 2005; Ottersbach and Dzierzak, 2005). Clearly this new development raises the question of the origin of these stem cells: are they extrinsic or intrinsic? Other results (Ziegler et al., 2006; Corbel et al., 2007) now indicate that clonogenic progenitors become committed in situ, rather than colonize the placenta. The progress of this novel issue will be reviewed here.

\section{Developmental assembly of the mouse placenta}

The fetal component of the placenta results from the fusion of two independent structures (Fig. 1). One derives from the early embryo outermost layer, the trophectoderm. The other is the allantois, a mesodermal appendage emitted by the caudal end of the primitive streak, as the embryo undergoes gastrulation. At E3.5 the trophectoderm encloses the inner cell mass (ICM), the structure that will give rise to the embryo, and the blastocoelic cavity. The polar region of the trophectoderm, in contact with the ICM, proliferates, and becomes the ectoplacental cone. The latter structure delaminates giving rise to the chorionic plate, which faces the developing embryo. Meanwhile the allantois grows out

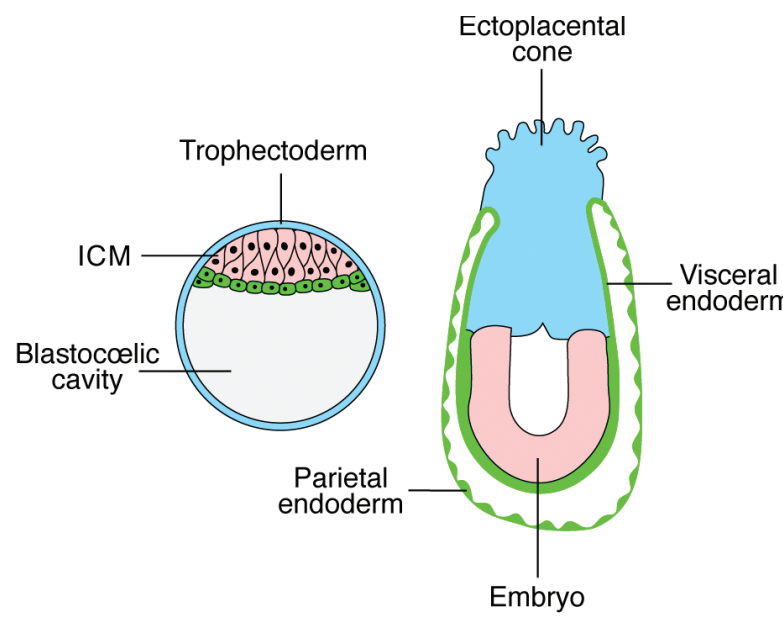

E 3.5

Blastocyst
E 6.0

Headfold stage

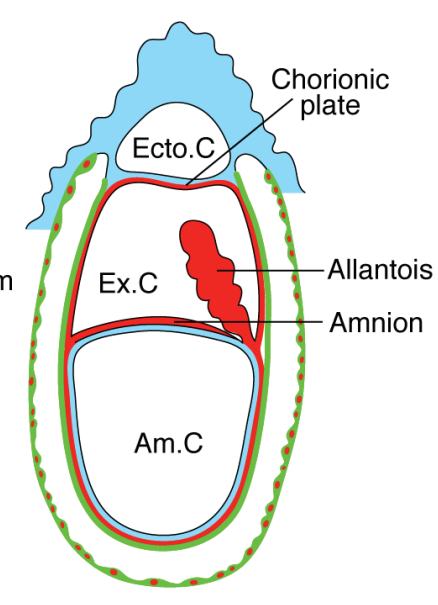

$$
\begin{gathered}
\text { E } 7.5-\text { E8 } \\
<6 \mathrm{SP}
\end{gathered}
$$

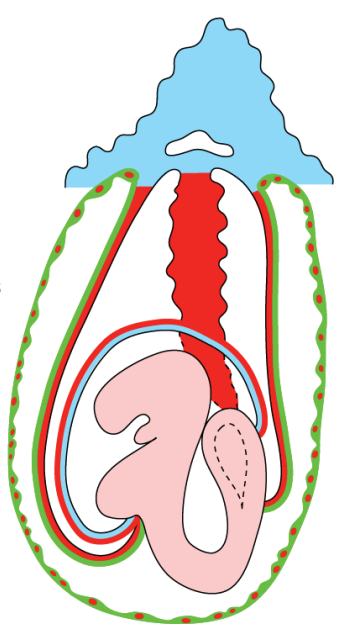

E 8.75

Fig. 1. Formation of the mouse placenta (modified from Kaufman (Kaufman, 1998), and from Rossant and Cross (Rossant and Cross, 2001). Color code: blue = ectoderm; green = endoderm; red = mesoderm; pink = embryo. E3.5 inner cell mass (ICM) pink with green primitive endoderm. E6, The trophectoderm overlying the ICM has become the ectoplacental cone. E7.5-E8, prior to the 5 somite stage. The chorionic plate is separated from the trophectoderm by the exocoelomic cavity. (Ex.C). The allantois grows out from the caudal embryo into the exocoelomic cavity. Ecto.C, ectoplacental cavity; Am.C, amniotic cavity; E8.75, the allantois has fused to the ectoplacental cone. 
form the caudal end of the primitive streak into the exocoelomic cavity. By the stage of 6 to 8 pairs of somites (depending on individual embryos), the allantois contacts the chorionic plate and attaches to it. In the next step, ruffles, expressing the transcription factor-encoding gene Glial cell missing (Gcm 1), appear in the chorionic plate. Endothelial buds are emitted by the allantois at the points of contact with these ruffles. Gene expression antedates the formation of the ruffles, suggesting that ingrowth of the endothelial digits is induced by the contact with Gcm1-expressing focal points in the chorionic plate (Anson-Cartwright et al., 2000). The endothelial buds emitted by the allantois thereafter interdigitate with maternal endothelia within a structure called the labyrinth, where fetal and maternal endothelia are separated by two layers of chorionic plate-derived synciotrophoblasts. Interestingly the process known as vasculogenesis (Risau and Lemmon, 1988) i.e., commitment of mesoderm to angioblasts, occurs in the allantoic mesoderm (Downs et al., 1998). Thus the endothelia of cord blood vessels (umbilical artery and vein) and of fetal blood vessels in the placenta derive from the allantois.

\section{The avian lead: hematopoietic and angioblastic poten- tial of the allantois}

The avian model previously contributed several major concepts about the ontogeny of the hematopoietic system, which were later validated in other classes of vertebrates. The multiple steps involved in blood formation could be clearly defined because the avian embryo is conveniently accessible to experimental manipulations, and because the quail/chicken system (Le Douarin, 1973) allows to trace the origins and fate of cell lineages. Intra-embryonic HSC were thus discovered in chimeras constructed between a quail embryo and a chicken yolk sac (DieterlenLièvre, 1975; review in Dieterlen-Lièvre et al., 2001; see also Dzierzak and Medvinsky, 2008). In the early analyses of these hematopoietic chimeras, the origin of cells was determined by means of the quail/chicken nuclear difference. The MB1 and QH1 antibodies, which recognize endothelium and blood cells (with the exception of the erythroid lineage) (Péault et al., 1983, Pardanaud et al., 1987) in the quail and not the chicken, subsequently made cell tracing in these blood chimeras remarkably efficient.

As the avian allantois (Fig. 2A) produces a large amount of erythrocytes when explanted in liquid medium (Dieterlen-Lièvre, unpublished data), a possible hematopoietic potential was explored. Interestingly, endothelium-contained collections of red cells, very similar to yolk sac blood islands, were present in the allantoid bud prior to circulation closure (Caprioli et al., 1998, 2001). Pre-circulation quail allantoic buds were grafted ectopically in the coelom of stage-matched chicken. Cells from the bone marrow of E15-16 hosts, by then fully functional, were sorted by cytofluorimetry on the basis of QH1 expression (Fig. 2B). A significant proportion of quail cells was found.

These experiments modulate the former conclusion drawn from the study of yolk sac chimeras, namely that HSC come from the embryo proper. The allantois, a late forming structure in birds, grows out from the posterior intestinal portal of the grafted embryo, and is thus quail in yolk sac chimeras, so that blood cells produced in these chimeras by the aortic region or the allantois cannot be distinguished from each other. Nonetheless as various experimental approaches in several classes of vertebrates have

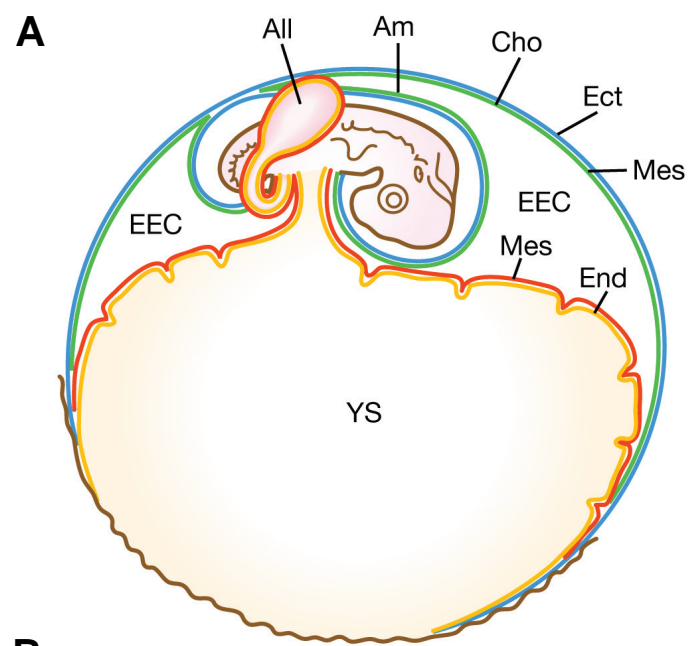

B

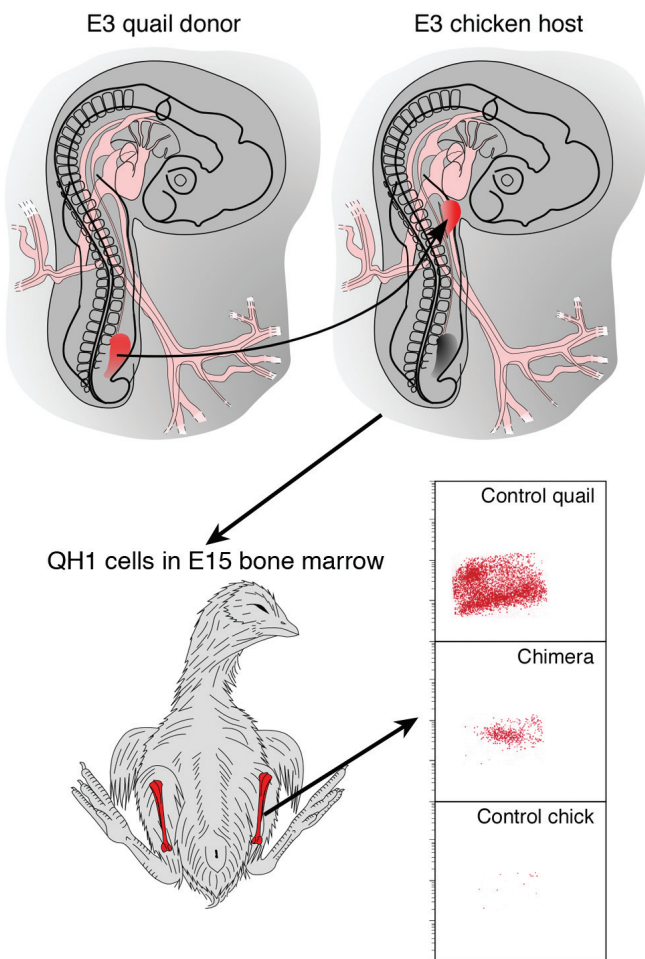

Fig. 2. The avian allantois produces HSC (Caprioli et al., 1998, 2001). (A) Schematic representation of the E4 avian embryo (modified from Lilly's development of the chick). Color code: blue = ectoderm (Ect); yellow = endoderm (End); red = vasculogenetic, hematogenous mesoderm (Mes); stippled white = non-vasculogenetic, non-hematogenous mesoderm (Mes). The allantois (All) is beginning to fuse with the outer layer of the amnion (Am), or chorion (Cho), giving rise to the chorioallantoic membrane, which ensures the embryo's gas exchanges. Note that the process is similar to trophectoderm fusion in the mammalian embryo. $E E C=$ extra-embryonic coelom, YS = yolk sac. (B) Experimental demonstration of the hematogenous potential of the avian allantois. The unvascularized quail allantoic rudiment was grafted into the coelomic cavity of a chicken host. At E15, bone marrow cell suspensions were analyzed by cytofluorimetry, using the quail-specific, hemangioblastic lineage-specific $\mathrm{QH} 1$ antibody (bottom right box). As a mean $4.6 \%$ bone marrow cells were quail. In some embryos up to $8 \%$ of bone marrow cells were quail, although the host hematopoietic system was not subjected to any depressing treatment in these experiments. 
firmly substantiated the generation of HSC by the aorta (review in Durand and Dzierzak, 2005), the role of this blood vessel cannot be questioned. However the finding that the allantois is involved in hematopoietic cell production indicates that the process of HSC emergence is more extensive time-wise and space-wise than previously thought.

Finally it is interesting to point out that the cytological study of the bone marrow of quail allantois-engrafted chicken hosts uncovered a mix of quail hematopoietic and endothelial cells. As both lineages are known to derive in the bone marrow from extrinsic progenitors (Jotereau and Le Douarin, 1978; Pardanaud et al., 1989), the question of the nature of the colonizing cells is raised, eliciting the attractive hypothesis that these cells might be hemangioblasts, i.e., common progenitors for both lineages (Eichmann et al., 1997; Choi et al., 1998; Huber et al., 2004; Zovein et al., 2008, Chen et al., 2009; Eilken et al., 2009; Lancrin et al., 2009).

\section{Hematopoietic activity of the mouse placenta}

We proposed the hypothesis of a hematopoietic role of the mouse placenta (Alvarez-Silva et al., 2003), on the basis of the above-described blood forming potential of the avian allantois (Dieterlen-Lièvre et al., 2001).

The first approach we implemented to support this hypothesis consisted in detecting short-term progenitors (Colony Forming Cells, CFC) by means of in vitroclonogenic assays (Alvarez-Silva etal., 2003). The fetuses were obtained from a cross between wild type females and males carrying one allele of a GFP transgene making it possible to diagnose whether CFC derived from the fetal or the maternal component of the placenta (Fig. 3).

Testing began at the stage of 5 pairs of somites. The first nonmaternal progenitors were found in the placenta of embryos with 20 pairs of somites (E9), antedating by about 48 hours the colonization of the liver which is initiated between the stages of 28 and 32 somites according to Houssaint (1981). With respect to the production in the para-aortic splanchnopleura which begins at the 18 pairs of somites stage, placental HSC appearance was slightly delayed. Progenitors were still present at E17, the time limit of the
TABLE 1

\section{COMPARED CELLULARITY AND PROGENITOR CONTENT OF HEMATOPOIETIC SITES}

\begin{tabular}{|c|c|c|c|c|c|c|}
\hline & \multicolumn{2}{|c|}{ Yolk sac } & \multicolumn{2}{|c|}{ Placenta } & \multicolumn{2}{|c|}{ Fetal liver } \\
\hline \multicolumn{7}{|c|}{ Number of nucleated cells } \\
\hline E10 & $4 \times 10^{4}$ & \multirow{3}{*}{ x 1.4} & $34 \times 10^{4}$ & $\uparrow$ & $65 \times 10^{2}$ & \multirow{3}{*}{$\varlimsup_{x\left[1.3 \times 10^{3}\right]}$} \\
\hline E12 & $8 \times 10^{4}$ & & $31 \times 10^{4}$ & \multirow{2}{*}{$\times 1.4$} & $63 \times 10^{3}$ & \\
\hline E15 & $7 \times 10^{4}$ & & $48 \times 10^{4}$ & & $38 \times 10^{4}$ & \\
\hline E17 & $7 \times 10^{4}$ & $\downarrow$ & $58 \times 10^{4}$ & $\downarrow$ & $96 \times 10^{5}$ & $\downarrow$ \\
\hline \multicolumn{7}{|c|}{$\begin{array}{l}\text { Number of clonogenic progenitors, all types merged (CFU-GEMM + BFU-E + CFU-GM) per } \\
\text { organ. (Values were rounded up to the next whole number) }\end{array}$} \\
\hline E10 & 30 & \multirow{3}{*}{$\times 1.7$} & 340 & \multirow{3}{*}{ x 3.8} & 0.3 & \multirow{2}{*}{$\uparrow_{x\left[4 \times 10^{4}\right]}$} \\
\hline E12 & 80 & & 430 & & 315 & \\
\hline E15 & 40 & & 1000 & & 4800 & \\
\hline E17 & 50 & $\downarrow$ & 1300 & $\downarrow$ & 11200 & $\downarrow$ \\
\hline
\end{tabular}

Double headed arrows show the amplification factor between stages.

study, their number actually peaking at that stage. Thus the myelo-erythroid potential of the placenta is sustained much longer than that of the AGM, in which the short-lived production of progenitors stops by the stage of 42 somites (Medvinsky and Dzierzak, 1996).

Table 1 compares the quantitative aspects of progenitor output from $\mathrm{E} 10$ to $\mathrm{E} 17$ in different organs. Within this time course, yolk sac supports a modest amplification $(x 1.7)$ as well as placenta (x3.8). In contrast, liver is a site where clonogenic progenitors multiply vigorously: 35 -fold when E17 is compared to E12 (at E10 it can be considered that colonization has hardly begun). However, the proportion of colony types is strikingly different in placenta and liver at all stages, the former being richer in early progenitors. While the majority of the colonies detected in this assay reach their maximum development by day 14 of culture, a few colonies of the so-called 'High Proliferation Potential' (HPP) type were found in cultures from E12-E15 placenta and liver, with twice higher frequency in the placenta. These HPP-CFC were very large (more than $0.5 \mathrm{~mm}$ in diameter), multilineage and replatable for at least 60 days. Thus, while the liver supports both progenitor amplification and commitment to differentiation, the modestly growing hematopoietic population in the placenta re-
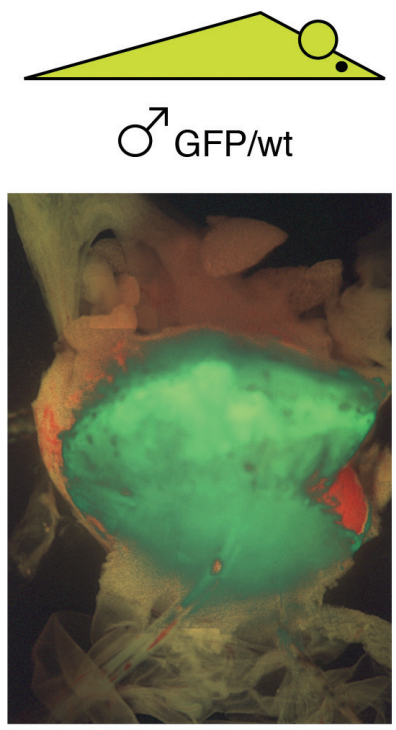

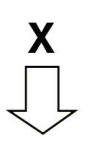

$1 / 4 \mathrm{GFP}^{+}$embryos

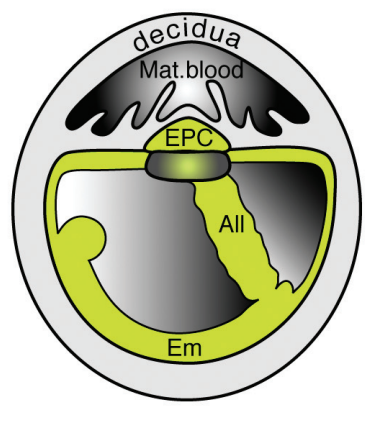

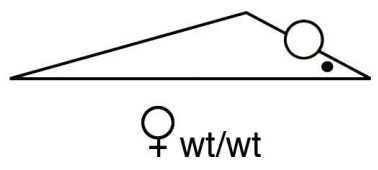

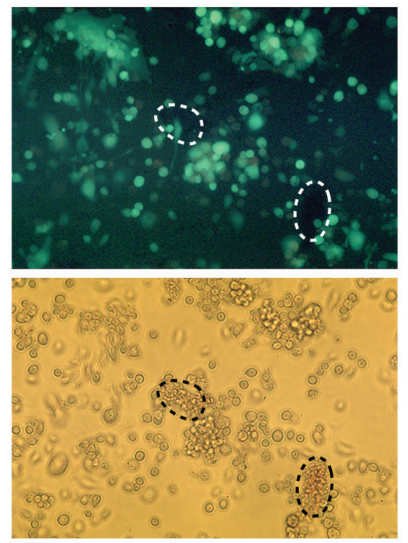

Fig. 3. Hematopoietic potential of mouse placenta detected by clonogenic tests (AlvarezSilva et al., 2003). Experimental scheme. In GFP+ embryos carrying one allele of the Green Fluorescent Protein encoding transgene, the fetal component of the placenta fluoresces in green, while the wild type maternal component is visible in photonic light in the double exposure, bottom left. Note that some erythroid colonies, faint red in the phase contrast photograph, have lost GFP expression (stippled circles in the two bottom right boxes). All, allantois; Em, embryo; EPC, ectoplacental cone; Mat.blood, maternal blood. 
A
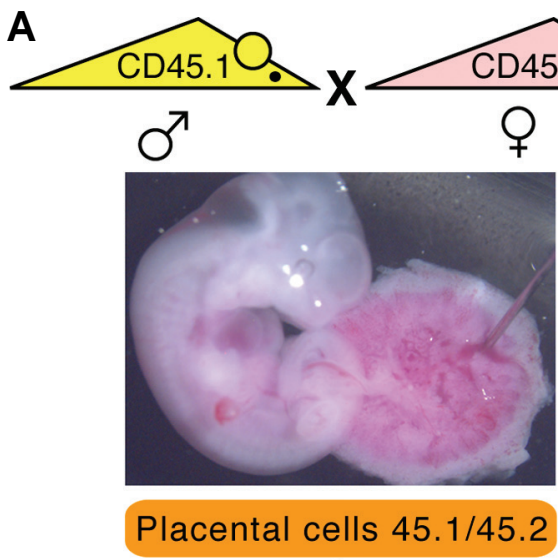

$+$

$1.10^{5}$ cells adult BM 45.1

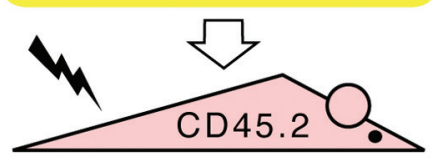

$\downarrow$

Secondary

transplantation

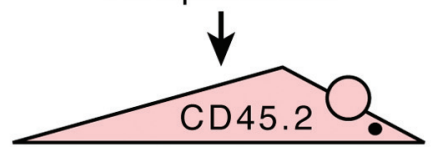

B

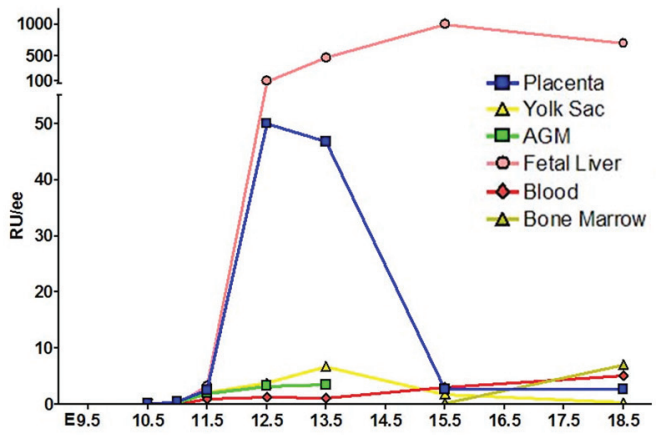

C

\begin{tabular}{|l|c|c|c|c|}
\hline & PI & $\begin{array}{c}\text { Caudal } \\
\text { Half or } \\
\text { AGM } 1\end{array}$ & FL & Control \\
\hline E10.5 & $\begin{array}{c}0.103 \\
(6 / 33)\end{array}$ & $\begin{array}{c}0.107 \\
(9 / 36)\end{array}$ & $0^{2}$ \\
\hline E11 & $\begin{array}{c}0.48 \\
(8 / 27)\end{array}$ & $\begin{array}{c}0.31 \\
(9 / 22)\end{array}$ & $\begin{array}{c}0.05 \\
(1 / 19)\end{array}$ & $0^{3}$ \\
\hline E11.5 & $\begin{array}{c}2.5 \\
(18 / 23)\end{array}$ & $\begin{array}{c}2.0 \\
(15 / 19)\end{array}$ & $\begin{array}{c}3.3 \\
(15 / 15)\end{array}$ & ND \\
\hline E12.5 & $\begin{array}{c}50 \\
(23 / 33)\end{array}$ & $\begin{array}{c}3.3 \\
(5 / 15)\end{array}$ & $\begin{array}{c}93.3 \\
(14 / 25)\end{array}$ & $0^{4}$ \\
\hline
\end{tabular}

1 Depending on the stage

2 Cephalic half of the embryo or decidua

3 Caudal half of the embryo without AGM or decidua

4 Decidua

PI : placenta FL : fetal liver ND : no determination
Fig. 4. In vivo reconstitution experiments (Gekas et al., 2005). (A) Experimental scheme. CD45.1/2 heterozygous fetal placental cells were injected into homozygous CD45.2 irradiated adults, along with supportive adult bone marrow CD45.1 cells. Six months later CD45.1/2 cells from the primary recipients were transplanted into secondary recipients. After each reconstitution, cells from bone marrow, spleen and thymus were phenotyped and tested for colony forming potential. Cells of placental origin proved capable of repopulating primary and secondary hosts. (B,C) Developmental reconstituting potential compared between different organs (Gekas et al., 2005, Mikkola et al., 2005). (B) the evolving profiles of RU/ee - Reconstituting units per embryo equivalent calculated as [(reconstituted recipients/ total recipients)/transplanted dose]are specific for each organ. In placenta and fetal liver the values display a sudden early increase. Liver remains rich in $R U$ until E18.5, at the end of the experiment. Placenta peaks at E12.5 and loses all RU by E15.5. AGM as well as yolk sac and blood retain lownumbers at all times.

AGM harbours RU until E13.5 only. The organ specific differences in the early stages (hardly visible in the graph) can be appraised from the table below. (C) numbers of RU/ee at early stages are displayed. In brackets: number of reconstituted animals/number of injected animals. RU appear simultaneously in the placenta and AGM, and 24 hours later in the fetal liver. The AGM numbers remain low at all times. The fetal liver soon overtakes the placenta. The caudal half of the embryo (below the umbilicus) was used at E10.5, the AGM was dissected at other stages. The cephalic half of the embryo (above the umbilicus), or the caudal half minus the AGM, or the uterine decidua were used as negative controls.

tains an immature character all along. A recent study demonstrated that multipotent as well as myeloid- and erythroid-committed progenitors were present in the human placenta (Barcena et al., 2009).

Long term repopulating (LTR)-HSC were monitored by means of in vivo reconstitution assays (Fig. 4A) (Gekas et al., 2005; Ottersbach and Dzierzak, 2005). The results of our own endeavor were reviewed in detail elsewhere (Mikkola et al., 2005). Briefly fetal cells were traced using heterozygotes for the alleles of the CD45 pan-hematopoietic antigen. The kinetics of LTR-HSC, which were analyzed from E10.5 to E18.5, have some common points with that of CFC plus some distinctive traits (Fig. 4A). HSC, capable of contributing to the blood of irradiated adults, appeared simultaneously in the placenta and caudal half (AGM) of the embryo, and only 24 hours later in the fetal liver. The increase thereafter was modest in the caudal half, while it was striking in both placenta and fetal liver. Later on LTR-HSC reached a high level plateau in the liver and then dropped in the placenta, disappearing by E15.5 (Fig. 4B).

By comparison with placenta and fetal liver, LTR-HSC numbers found in the AGM were very small (Fig. 4C). Medvinsky's group raised the problem of the major increase in HSC numbers which occurs in the liver between E11 and E12, stating that it could hardly be explained by incoming cells from the AGM, whose output is small, or by mitotic expansion within the liver in such a short time (Kumaravelu et al., 2002). The placental source may answer this issue.

The placenta reconstituting cells were shown to be multipotent, they displayed a CD34+ ${ }^{+}$c-Kit high phenotype, and they were able to reconstitute secondary hosts (Gekas et al., 2005). They were Sca $1^{+}$as well (Ottersbach and Dzierzak, 2005).

\section{Are placental hematopoietic stem cells born in situ?}

In view of the diverse role of hematopoietic sites during development, it appeared crucial to find out whether placental HSC arise in situ, and hence to carry out tests prior to blood circulation. The latter event occurs at E8.5 (Palis et al., 1999), around the stage of 7 somites at about the time when the allantois fuses to the chorionic plate. If indeed the placenta is able to produce HSC, the component likely to be involved is the allantois, which undergoes vasculogenesis, i.e., tissue-autonomous endothelium development (Downs et al., 1998). However when Downs et al. (1998) looked for signs of erythropoiesis in pre-fusion allantois either ex vivo or after short term in toto culture, they reported, at the 6-somite pair stage, only a few benzidine-positive cells, whose number slightly increased in culture. Progenitor activity in cell populations isolated from 1 to $16 \mathrm{sp}$ allantoises was 
A
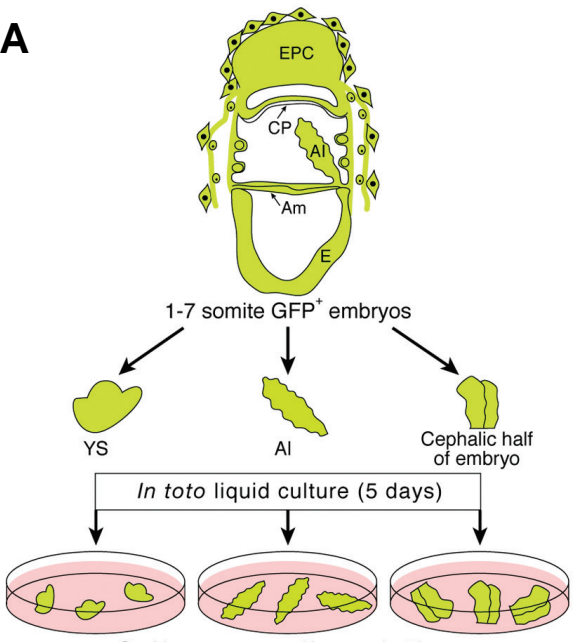

Collagenase dissociation

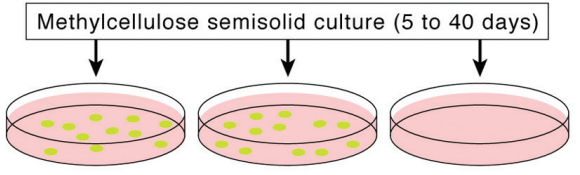

Colony counting and follow up (fluo/phase)

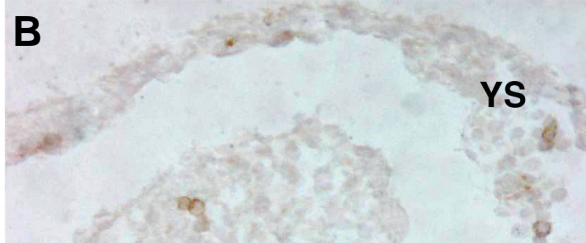

Al
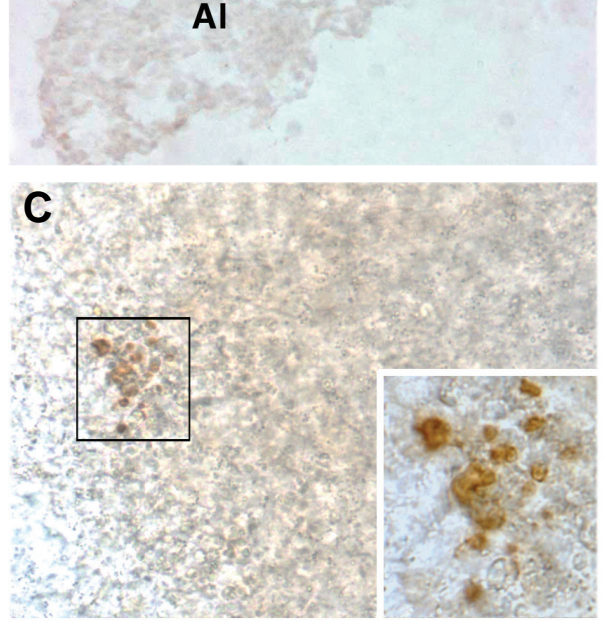

Fig. 5. Detection of the hematogenous potential of the pre-fusion allantois (Corbel et al. 2007). (A) Experimental scheme. (B,C) CD41 expression. (B) Non-cultured 5sp allantois (Al) and yolk sac (YS) in a transverse section of the conceptus. (C) $4 s p$ allantoises cultured in toto for 5 days.

also searched unsuccessfully by others (Palis et al., 1999). As we had found that the first progenitors appeared in the placenta at the 20 somite stage (Alvarez-Silva etal., 2003), we reasoned that, like in the P-Sp experiments (Cumano et al., 1996), their commitment from much earlier rudiments might be elicited only through the culture protocol implemented earlier, in which in totopreculture is followed by dissociation into single cells and by seeding in a semisolid medium for the identification of clonal progenitors (2-step culture) (Fig. 5A).

In these conditions, cells from the pre-fusion allantoises did give rise to hematopoietic colonies that belonged to different types, erythroid, myeloid and mixed (Fig. 6). In the case of the erythroid lineage, clusters and colonies deriving from Erythroid (Ery)-CFC were identified as well as colonies derived from burst forming unit-erythroid (BFU-E). In the case of the myeloid lineage,

huge macrophage colonies developed and mixed erythro-monocytic colonies were also observed. These various clonal hematopoietic progenitors could be obtained from prefusion allantoises as early as the $1 \mathrm{sp}$ stage, i.e., long before the establishment of circulation (Corbel et al., 2007). While all 2-step cultured allantoises gave rise to colonies, neither the number nor the assortment of colony types were related to the embryonic stage of the buds, indicating that the commitment must be a random event. This is easily explained by the small number of cells in the allantoic buds at these early stages ( 0 to 6 somites).

The hematogenic capacity of the early allantoic bud is further indicated by the presence of CD $41^{+}$cell clusters, which were detected by immunocytology at the $4 \mathrm{sp}$ stage. CD41 (also called GPIlb-IIla or $\alpha$ llb $\beta 3$ ) is an integrin now considered as a hallmark of embryonic and fetal hematopoietic progenitors (Corbel and Salaün, 2002; Corbel et al., 2005; Emanbokus and Frampton, 2003; Mikkola et al., 2003; Ferkowicz et al., 2003). At that time $\mathrm{CD} 41^{+}$cells were very few, 3 to 10 cells per allantois (Fig. 5B). These CD41+ clusters enlarged significantly during the 3D culture period, as the clonogenic potential emerged (Fig. 5C).

The hematopoietic potential of the pre-fusion allantois was examined by Ziegler et al., 2006). The experimental approach was similar, using an in toto culture period, in which the whole allantoic buds were explanted in liquid medium on an OP9 feeder layer for 2 days prior to dissociation for clonogenic assays. Myeloid and erythroid potential was demonstrated and the erythroid colonies were shown to synthesize adult $\beta$ major hemoglobin. The Runx1 transcription factor, whose expression is required for HSC emergence (Chen et al., 2009), was expressed weakly in the allantoic bud at explantation and increased after in toto culture. Importantly Runx1 -/- allantoic buds did not give rise to colonies. Moreover the authors demonstrated that the chorionic plate mesoderm expertly isolated from the ectoplacental cone (EPC) has a hematogenic potential. In our own experiments, we were
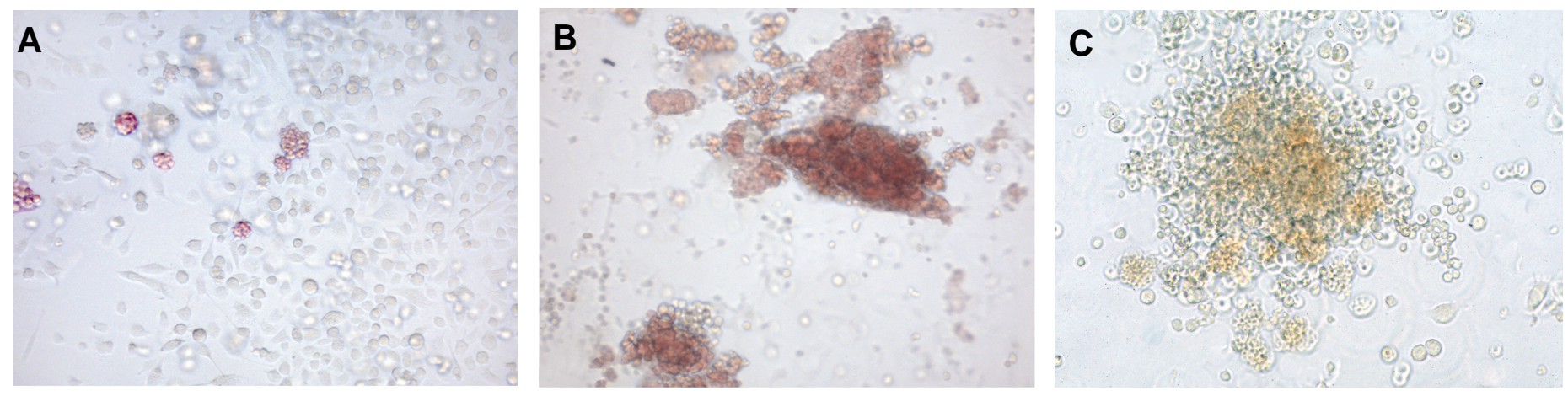

Fig. 6. Erythroid, myeloid and multipotent progenitor potential in pre-fusion allantois. (A) Erythroid colonies inside a large myeloid colony from $1 \mathrm{sp}$ allantoises. In toto culture, 5 days; semisolid culture, 7 days. (B) BFU-E colony from 3-4sp allantoises. In toto culture, 5 days; semisolid culture, 16 days (Corbel et al., 2007). (C) Mixed colony from 5sp allantoises. In toto culture, 5 days; semisolid culture, 7 days (Corbel et al., 2007). 
able to obtain clonogenic progenitors from the EPC but did not pinpoint their origin. Using analogous methological approaches, the two pieces of work converge to attribute a hematogenic potential to mesoderm from two distinct components of the future placenta.

In order to monitor in vivo whether HSC found in the placenta are generated in situ or are merely imported via circulation, Rhodes et al. (2008) utilized the Ncx1 knockout mouse model. Ncx1-/-embryos have no heartbeat due to a defect in the sodiumcalcium exchange pump and do not survive beyond E10.5 (Koushik et al., 2001). Rhodes et al.'s analysis showed that HSC development is initiated in the placenta vasculature independently of blood flow. Thus these authors confirm that the placenta is not only a niche for HSC but a true site of HSC generation.

\section{Conclusion and perspectives}

The body of experiments described here point to the placenta as a major player in fetal blood formation. Compared to the periaortic region, its activity as a provider of progenitors and of HSC is initiated at about the same time, but lasts longer and is much more important. Thus while the HSC put out by the AGM region certainly contribute to the initial colonization of the liver, placental HSC must participate in parallel to the beginning of the colonization process and ensure most of it later. Samokhvalov etal. (2007) generated Runx1/LacZ inducible mice to label the hematopoietic lineage at selected stages of development. They found that cells committed in the yolk sac colonized the umbilical cord, concluding that vessels of this structure may be a niche where to extrinsic blood progenitors migrate and differentiate. In our own experiments the allantois was retrieved prior to circulation, so that at least part of the progenitors found in this rudiment are born in situ.

The sites previously identified as hematogenous have a common feature: yolk sac and P-Sp are composed of mesoderm associated to endoderm. The latter germ layer is known to produce 'ventralizing' signals which are involved, among other processes, in commitment to hematopoiesis. Indeed the presence of endoderm appears to be an absolute requirement for blood formation (Miura and Wilt, 1969; Risau and Flamme, 1995; Pardanaud et al., 1996; Pardanaud and Dieterlen-Lièvre 1999). However the mouse allantois, which according to our data is at the origin of a large part of the placental HSC, is purely mesodermal (Inman and Downs, 2006). As an explanation for this apparent paradox, we propose that the endodermal contact experienced by allantoic mesoderm, as it emerges from the primitive streak, may allow the signaling event to occur (Belaoussof et al., 1998). The allantois and, in its wake, the placenta clearly belong to a continuum which includes P-Sp/AGM and the fetal arteries in the region of the umbilicus, where hematopoiesis was described (Tavian et al., 1999; de Bruijn et al., 2000).

The description of these novel sites for hematopoiesis and commitment opens a number of perspectives. For instance P-Sp cells do not display long term reconstituting potential of irradiated recipients, while AGM cells do. It is likely that as development proceeds cells produced by the allantois/placenta undergo the same phenotypic maturation underlying this change in potential, from weak to adult type expression of MHC class I antigens (Cumano et al., 2001). In other words, when early allantois cells will be probed for reconstitution potential as the next step in their characterization, they will probably, like P-Sp cells (Cumano et al., 2001), prove unable to reconstitute immunologically competent irradiated adults since they should be rejected by natural killer cells.

Other prospects concern the 3D cell interactions required for the commitment to hematopoiesis described above. The molecular signals involved are currently studied in the embryonic stem cell-derived embryoid body model (Robertson et al., 2000). It will be important to explore this aspect in the embryo/fetus proper. The allantois may be a particularly well suited structure for the analysis of this signaling process at the cellular level, not only because it is easy to retrieve, but also because in these early stages one of its main functions may be the hematogenous one.

It is essential to probe whether the EPC plays a role in the evolution of this activity after fusion. The placenta being a factory for growth factors, fusion is likely to promote HSC output, and the trophoblastic lineage may be involved.

The release of HSC by the placenta into the cord blood needs to be studied until birth, hopefully allowing to identify the origin of cord blood cells. The circulatory pathways responsible for the hypothezised traffic between placenta and fetal liver (Mikkola et al., 2005) open up another line of research. Other preferential pathways of migration and homing may also be at work, possibly due to privileged circulatory links and differential attractivity of rudiments for HSC. In this respect, the transgenic mouse model devised by Iruela-Arispe's group (Zovein et al., 2008) may yield further critical information since it allows permanent labeling of blood cells produced at a selected developmental stage. This model may be the mammalian equivalent of the quail/chick tracing system.

To sum up the placenta is now established as a new player in developmental hematopoiesis. As recently reviewed hematopoietic development occurs in different sites: yolk sac, P-Sp/AGM and chorion-allantoic placenta (Dzierzak and Speck, 2008). The most recent experiments show that some of the HSC involved become committed in situ in one of the placenta's component structures adding this site to the few able to support this event.

\section{Acknowledgments}

Marcio Alvarez-Silva, Hanna Mikkola, Christos Gekas and Stuart Orkin entered into this project with enthusiasm. FD wishes to emphasize their major contributions throughout and after this collaborative effort. We are grateful to Sophie Gournet for her efficient help with illustrations, to Patricia Diabangouaya for technical support and to Florence Mitchell for editing the text.

\section{References}

ALVAREZ-SILVA M., BELO-DIABANGOUAYA P., SALAÜN J. and DIETERLENLIÈVRE F. (2003). Mouse placenta is a major hematopoietic organ. Development 130:5437-5444.

ANSON-CARTWRIGHT L., DAWSONK., HOLMYARD D., FISHER S.J., LAZZARINI R.A. and CROSS J.C. (2000). The glial cells missing-1 protein is essential for branching morphogenesis in the chorioallantoic placenta. Nature Genetics 25:311-314.

BARCENA A., KAPIDZIC M., MUENCH M.O., GORMLEY M., SCOTT M.A., WEIER J.F., FERLATTE C. and FISHER S.J. (2009). The human placenta is a hematopoietic organ during the embryonic and fetal periods of development. Dev. Biol. 327:24-33.

BEAUPAIN D., MARTIN C. and DIETERLEN-LIÈVRE F. (1979). Are developmental hemoglobin changes related to the origin of stem cells and site of erythropoie- 
sis? Blood 53:212-225.

BELAOUSSOFF M., FARRINGTON S.M., and BARON M. (1998). Hematopoietic induction and respecification of A-P identity by visceral endoderm signaling in the mouse embryo. Development 125:5009-5018.

CAPRIOLI A., JAFFREDO T., GAUTIER R., DUBOURG C. and DIETERLENLIĖVRE F. (1998). Blood-borne seeding by hematopoietic and endothelial precursors from the allantois. Proc. Natl. Acad. Sci. USA 95:1641-1646.

CAPRIOLI A., MINKO K., DREVON C., EICHMANN A., DIETERLEN-LIĖVRE F and JAFFREDO T. (2001). Hemangioblast commitment in the avian allantois: cellular and molecular aspects. Dev. Biol. 238:64-78.

CHEN, M. J., YOKOMIZO, T., ZEIGLER, B. M., DZIERZAK, E., and SPECK, N. A. (2009). Runx1 is required for the endothelial to haematopoietic cell transition but not thereafter. Nature 457: 887-891.

CHOI K., KENNEDY M., KAZAROV A., PAPADIMITRIOU J.C., and KELLER G. (1998). A common precursor for hematopoietic and endothelial cells. Development 125:725-732.

CORBEL C., and SALAÜN J. (2002). $\alpha$ llb integrin expression during development of the murine hemopoietic system. Dev. Biol. 243:301-311.

CORBEL C., VAIGOT P., and SALAÜN J. (2005). $\alpha$ llb integrin, a novel marker for hemopoietic progenitor cells. Int. J. Dev. Biol. 49:279-284.

CORBEL C., SALAÜN J., BELO-DIABANGOUAYA P., and DIETERLEN-LIĖVRE, F. (2007). Hematopoietic potential of the pre-fusion allantois. Dev. Biol. 301:478488.

CUDENNEC C., THIERY J.P. and LE DOUARIN N. (1981). In vitroinduction of adult erythropoiesis in early mouse yolk sac. Proc. Natl. Acad. Sci. USA 7: 24122416.

CUMANO A., DIETERLEN-LIĖVRE F., and GODIN I. (1996). Lymphoid potential, probed before circulation in mouse, is restricted to caudal intraembryonic splanchnopleura. Cel/86:907-916.

CUMANO A., FERRAZ J.C., KLAINE M., DI SANTO J.P., and GODIN I. (2001). Intraembryonic, but not yolk sac hematopoietic precursors, isolated before circulation, provide long-term multilineage reconstitution. Immunity 15:477485.

DANCIS J., JANSEN V., GORSTEIN F., and DOUGLAS G.W. (1968). Hematopoietic cells in mouse placenta. Am. J. Obstet. Gynecol. 100:1110-1121.

DANCIS J., JANSEN V., BROWN G.F., GORSTEIN F., and BALIS M.E. (1977). Treatment of hypoplastic anemia in mice with placental transplants. Blood 50:663-670.

de BRUIJN M.F., SPECK N.A., PEETERS M.C., and DZIERZAK E. (2000). Definitive hematopoietic stem cells first develop within the major arterial regions of the mouse embryo. EMBO J.19:2465-2474.

DIETERLEN-LIÈVRE F. (1975). On the origin of haemopoietic stem cells in the avian embryo: an experimental approach. J. Embryol. Exp. Morphol. 33:607619.

DIETERLEN-LIÈVRE F., PARDANAUD L., CAPRIOLI A., and JAFFREDO T. (2001). Non-yolk sac hematopoietic stem cells: the avian paradigm. In Zon LI, editor. Hematopoiesis. A Developmental Approach. Oxford University Press. pp. 201-208.

DIETERLEN-LIÈVRE F., and JAFFREDO T. (2009). Decoding the hemogenic endothelium in mammals. Cel/ Stem Cel/4:189-190.

DOWNS K.M., GIFFORD S., BLAHNIK M., and GARDNER R.L. (1998). Vascularization in the murine allantois occurs by vasculogenesis without accompanying erythropoiesis. Development 125:4507-4520.

DURAND C., and DZIERZAK E. (2005). Embryonic beginnings of adult hematopoietic stem cells. Haematologica 90:100-108.

DZIERZAK E., and OOSTENDORP R. (2001). Hematopoietic stem cell development in mammals. In Zon LI, editor. Hematopoiesis. A Developmental Approach. Oxford University Press pp. 209-217.

DZIERZAK E., and MEDVINSKY A. (2008). The discovery of a source of adult hematopoietic cells in the embryo. Development 135:2343-2346.

DZIERZAK E., and SPECK N.A. (2008). Of lineage and legacy: the development of mammalian hematopoietic stem cells. Nature Immunol. 9:129-136.

EICHMANN A., CORBEL C., NATAF V., VAIGOTP., BREANT C., and LE DOUARIN N.M. (1997). Ligand-dependent development of the endothelial and hemopoietic lineages from embryonic mesodermal cells expressing vascular endothelial growth factor receptor 2. Proc. Natl. Acad. Sci. USA 94:5141-5146.

EILKEN, H.M., NISHIKAWA, S-I. and SHROEDER, T. (2009). Continuous singlecell imaging of blood generation from haemogenic endothelium. Nature 457:896900.

EMANBOKUS N.R., and FRAMPTON J. (2003). The glycoprotein $\alpha$ llb molecule is expressed on early murine hematopoietic progenitors and regulates their numbers in sites of hematopoiesis. Immunity 19:33-45.

FERKOWICZ M.J., STARR M., XIE X., LI W., JOHNSON S.A., SHELLEY W.C, MORRISON P.R., and YODER M.C. (2003). CD41 expression defines the onse of primitive and definitive hematopoiesis in the murine embryo. Development 130:4393-4403

GEKAS C., DIETERLEN-LIÈVRE F., ORKIN S.H., and MIKKOLA H.K. (2005). The placenta is a niche for hematopoietic stem cells. Dev. Cel/8:365-375.

GODIN I., GARCIA-PORRERO J.A., COUTINHO A., DIETERLEN-LIÈVRE F., and MARCOS M.A. (1993). Para-aortic splanchnopleura from early mouse embryos contains B1a cell progenitors. Nature 364:67-70.

HOUSSAINT E. (1981). Differentiation of the mouse hepatic primordium. II. Extrinsic origin of the haemopoietic cell line. Cell. Differ. 10:243-252.

HUBER T.L., KOUSKOFF V., FEHLING H.J., PALIS J., and KELLER, G. (2004). Haemangioblast commitment is initiated in the primitive streak of the mouse embryo. Nature 432:625-630.

INMAN K.E., and DOWNS K.M. (2006). Brachury is required for elongation and vasculogenesis in the murine allantois. Development 133:2947-2959.

JAFFREDO T., GAUTIER R., EICHMANN A., and DIETERLEN-LIĖVRE, F. (1998). Intraaortic hemopoietic cells are derived from endothelial cells during ontogeny. Development 125:4575-4583.

JOHNSON G.R, and MOORE M.A. (1975). Role of stem cell migration in initiation of mouse foetal liver haemopoiesis. Nature 258:726-728.

JOTEREAU F.V. and LE DOUARIN N.M. (1978). The development relationship between osteocytes and osteoclasts: a study using the quail-chick nuclear marker in endochondral ossification. Dev. Biol. 63:253-265.

KAUFMAN M. The atlas of mouse development. London: Academic Press, 1998.

KOUSHIK S.V., WANG J., ROGERS R., MOSKOPHIDIS D, LAMBERT NA CREAZZO TL, and CONWAY SJ. (2001). Targeted inactivation of the sodiumcalcium exchanger (Ncx1) results in the lack of a heartbeat and abnormal myofibrillar organization. FASEB J. 15:1209-1211.

KUMARAVELU P., HOOK L., MORRISON A.M., URE J., ZHAO S., ZUYEV S., ANSELL J., and MEDVINSKY A. (2002). Quantitative developmental anatomy of definitive haematopoietic stem cells/long-term repopulating units ( $\mathrm{HSC}$ / $\mathrm{RUS}$ ): role of the aorta-gonad-mesonephros (AGM) region and the yolk sac in colonisation of the mouse embryonic liver. Development 129:4891-4899

LANCRIN C., SROCZYNSKA P., STEPHENSON C., ALLEN T., KOUSKOFF V. and LACAUD G. (2009). The haemangioblast generates haematopoietic cells through a haemogenic endothelium stage. Nature 457:892-895.

LE DOUARIN N.M. (1973). A Feulgen-positive nucleolus. Exp. Cell. Res. 77:459468.

LE DOUARIN N.M., and JOTEREAU F. (1973). Origin and renewal of lymphocytes in avian embryo thymuses through embryonic life in interspecific chimeras. Nature New Biol. 246:25-27.

LE DOUARIN N.M., HOUSSAINT E., JOTEREAU F.V., and BELO M. (1975). Origin of hemopoietic stem cells in embryonic bursa of Fabricius and bone marrow studied through interspecific chimeras. Proc. Natl. Acad. Sci. USA 72:2701 2705.

MEDVINSKY A.L., SAMOYLINA N.L., MULLER A.M., and DZIERZAK E.A. (1993) An early pre-liver intraembryonic source of CFU-S in the developing mouse. Nature 364:64-67.

MEDVINSKY A., and DZIERZAK E. (1996). Definitive hematopoiesis is autonomously initiated by the AGM region. Cel/86:897-906.

MELCHERS F. (1979). Murine embryonic B lymphocyte development in the placenta. Nature 277:219-221.

MIKKOLA H.K., FUJIWARA Y., SCHLAEGER T.M., TRAVER D, and ORKIN SH (2003). Expression of CD41 marks the initiation of definitive hematopoiesis in the mouse embryo. Blood101.508-516.

MIKKOLA H.K.A., GEKAS C., ORKIN S.H., and DIETERLEN-LIÈVRE F. (2005) Placenta as a site for hematopoietic stem cell development. Exp. Hematol. 
3:1048-1054.

MIURA Y., and WILT F.H. (1969). Tissue interaction and the formation of the first erythroblasts of the chick embryo. Dev. Biol. 19:201-211.

MOORE M.A.S., and OWEN J.J.T. (1965). Chromosome marker studies in the development of the haemopoietic system in the chick embryo. Nature208:958989.

MOORE M.A.S., and OWEN J.J.T. (1967). Stem cell migration in developing myeloid and lymphoid systems. Lancet 2:658-659.

OTTERSBACHK., DZIERZAKE. (2005). The murine placenta contains hematopoietic stem cells within the vascular labyrinth region. Dev. Ce//8:377-387.

PALIS J., ROBERTSON S., KENNEDY M., WALL C., and KELLER G. (1999). Development of erythroid and myeloid progenitors in the yolk sac and embryo proper of the mouse. Development 126:5073-5084.

PARDANAUD L., ALTMANN C., KITOS P., DIETERLEN-LIÈVRE F, and BUCK C.A. (1987). Vasculogenesis in the early quail blastodisc as studied with a monoclonal antibody recognizing endothelial cells. Development 100:339-349.

PARDANAUD L., YASSINE F., and DIETERLEN-LIĖVRE F. (1989). Relationship between vasculogenesis, angiogenesis and haemopoiesis during avian ontogeny. Development 105:473-485.

PARDANAUD L., LUTON D., PRIGENT M., BOURCHEIX L.-M., CATALA M., and DIETERLEN-LIÈVRE F. (1996). Two distinct endothelial lineages in ontogeny, one of them related to hemopoiesis. Development 122:1363-1371.

PARDANAUD L., and DIETERLEN-LIÉVRE F. (1999). Manipulation of the angiopoietic/hemangiopoietic commitment in the avian embryo. Development 126:617-627

PÉAULT B.M., THIERY J.P., and LE DOUARIN N.M. (1983). Surface marker for hemopoietic and endothelial cell lineages in quail that is defined by a monoclonal antibody. Proc. Natl. Acad. Sci. USA 80:2976-2980.

RISAU W., and LEMMON V. (1988). Changes in the vascular extracellular matrix during embryonic vasculogenesis and angiogenesis. Dev. Biol. 125:441-450.

RISAU W., and Flamme I. (1995). Vasculogenesis. Ann. Rev. Cell. Dev. Biol.
11:73-91.

ROBERTSON S.M., KENNEDY M., SHANNON J.M., and KELLER G. (2000). A transitional stage in the commitment of mesoderm to hematopoiesis requiring the transcription factor SCL/tal-1. Development 127:2447-2459.

RHODES K.E., GEKAS C., WANG Y., LUX C.T., FRANCIS C.S., CHAN D.N., CONWAY S., ORKIN S.H., YODER M.C., and MIKKOLA H.K.A. (2008). The emergence of hematopoietic stem cells is initiated in the placental vasculature in the absence of circulation. Cel/ Stem Cel/2:252-263.

ROSSANT J., and CROSS J.C. (2001). Placental development: lessons from mouse mutants. Nat. Rev. Genet. 2:538-548.

SAMOKHVALOV I.M., SAMOKHVALOVA N.I., NISHIKAWA S-I. (2007). Cell tracing shows the contribution of the yolk sac to adult haematopoiesis. Nature 446:1056-1061.

TAVIAN M., HALLAIS M.F., and PEAULT B. (1999). Emergence of intraembryonic hematopoietic precursors in the pre-liver human embryo. Development 126:793803.

TILL J., and McCULLOCH E.A. (1961). A direct measurement of the radiation sensitivity of normal mouse bone marrow cells. Rad. Res. 14:213-222.

TURPEN J.B. (2001). Dorsal hematopoiesis in fish hand amphibians. In Hematopoiesis. A Developmental Approach. (Ed. Zon LI). Oxford University Press. pp. 192-200.

YOSHIMOTO M., PORAYETTE P., and YODER M.C. (2008). Overcoming obstacles in the search for the site of hematopoietic stem cell emergence. Cell Stem Cell 4:583-586.

ZIEGLER B.M., SUGIYAMA D., CHEN M., GUOY., DOWNS K.M., and SPECKN.A. (2006). The allantois and chorion, when isolated before circulation or chorioallantoic fusion, have hematopoietic potential. Development 133:4183-4192.

ZOVEIN A.C., HOFMANN J.J., LYNCH M., FRENCH W.J., TURLO K.A., YANG Y., BECKER M.S., ZANETTA L., DEJANA E., GASSON J.C., TALLQUIST M.D. and IRUELA-ARISPE M.L. (2008). Fate tracing reveals the endothelial origin of hematopoietic stem cells. Cel/ Stem Cel/3: 625-636. 


\section{Further Related Reading, published previously in the Int. J. Dev. Biol.}

See our recent Special Issue Placenta edited by Joan S. Hunt and Kent L. Thornburg at: http://www.ijdb.ehu.es/web/contents.php?vol=54\&issue=2-3

Dynamic expression of Endoglin, a TGF-beta co-receptor, during pre-circulation vascular development in chick Cantas Alev, Brendan A.S. McIntyre, Kanako Ota and Guojun Sheng

Int. J. Dev. Biol. (2010) 54: 737-742 (doi: 10.1387/ijdb.092962ca)

Trophoblast phagocytic program: roles in different placental systems

Estela Bevilacqua, Mara-Sandra Hoshida, Andrea Amarante-Paffaro, Andrea Albieri-Borges and Sara Zago-Gomes Int. J. Dev. Biol. (2010) 54: 495-505 (doi: 10.1387/ijdb.082761eb)

Immune cells in the placental bed

Judith N. Bulmer, Paula J. Williams and Gendie E. Lash

Int. J. Dev. Biol. (2010) 54: 281-294 (doi: 10.1387/ijdb.082763jb)

Some historical aspects of understanding placental development, structure and function Lawrence D. Longo and Lawrence P. Reynolds

Int. J. Dev. Biol. (2010) 54: 237-255 (doi: 10.1387/ijdb.082774II)

Contemporary comparative placenta research - an interview with Allen Enders

Kent L. Thornburg and Joan S. Hunt

Int. J. Dev. Biol. (2010) 54: 231-236 (doi: 10.1387/ijdb.082837kt)

Epiblast-derived stem cells in embryonic and adult tissues

Maria P. De-Miguel, Francisco Arnalich-Montiel, Pilar Lopez-Iglesias, Alejandro Blazquez-Martinez and Manuel Nistal Int. J. Dev. Biol. (2009) 53: 1529-1540

A novel role of the glial fate determinant glial cells missing in hematopoiesis Cécile Jacques, Laurent Soustelle, István Nagy, Céline Diebold and Angela Giangrande Int. J. Dev. Biol. (2009) 53: 1013-1022

\section{Developmentally regulated expression of hemoglobin subunits in avascular tissues}

Fiona C. Mansergh, Susan M. Hunter, Jenny C. Geatrell, Miguel Jarrin, Kate Powell, Martin J. Evans and Michael A. Wride Int. J. Dev. Biol. (2008) 52: 873-886

Embryonic development of the proepicardium and coronary vessels Anna Ratajska, Elzbieta Czarnowska and Bogdan Ciszek Int. J. Dev. Biol. (2008) 52: 229-236

Interleukin-2 induces the proliferation of mouse primordial germ cells in vitro Cristina Eguizabal, Maria D. Boyano, Alejandro Díez-Torre, Ricardo Andrade, Noelia Andollo, Massimo De Felici and Juan Aréchaga Int. J. Dev. Biol. (2007) 51: 731-738
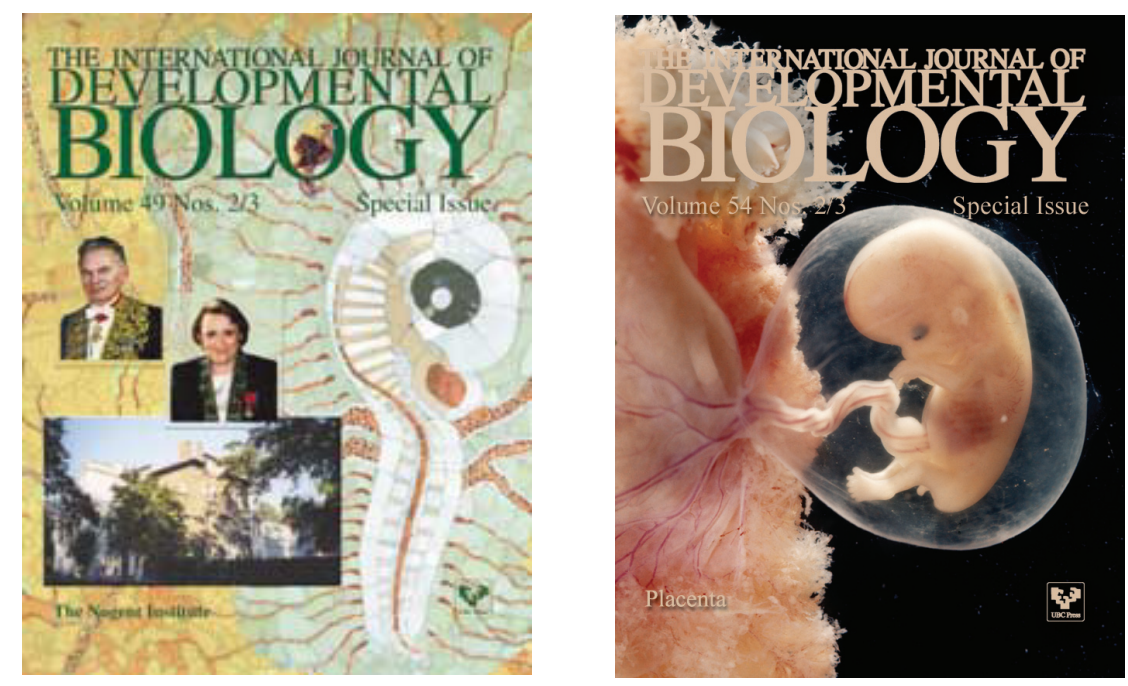

5 yr ISI Impact Factor $(2009)=3.253$
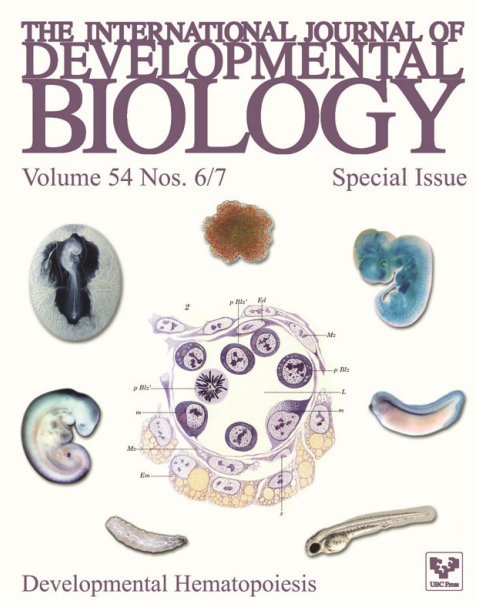